\title{
Effects of an Extract of Hawthorn on Arterial Blood Pressure in Anaesthetized Rats
}

\author{
Susan WS 1*, Miranda MW Wong, and Ricky YK Man \\ Department of Pharmacology and Pharmacy, Li Ka Shing Faculty of Medicine, The University of Hong Kong, Hong Kong SAR, P.R. China
}

\begin{abstract}
Hawthorn is an herbal medicine that has been used to treat various cardiovascular disorders, including angina, arrhythmias, congestive heart failure and hypertension. Its major components include flavonoids and oligomeric procyanidins. The present study examined the cardiovascular effects of a commercial available hawthorn extract (WS 1442) in anaesthetized rats. Male adult Sprague Dawley rats were anaesthetized and their carotid arteries were cannulated for blood pressure and heart rate measurement. After bolus intravenous injections of WS 1442 $\left(3.125,6.25,12.5\right.$ and $\left.25 \mathrm{mg} \cdot \mathrm{kg}^{-1}\right)$, mean arterial blood pressure $(104 \pm 3 \mathrm{mmHg})$ was reduced transiently in a dose-dependent manner. A greater effect on the diastolic than on the systolic blood pressure was observed. Heart rate was not significantly affected by all doses of WS 1442. Infusion of WS 1442 (10 and 28 mg.kg ${ }^{-1}$. min-1 for 7 $\mathrm{min}$ ) resulted in sustained decreases in mean arterial blood pressure without any significant changes in heart rate. Twenty minutes after the infusion, mean arterial blood pressure returned to the baseline values. Phenylephrine (1, 3 and $10 \mu \mathrm{g} \cdot \mathrm{kg}^{-1}$ ) dose-dependently increased arterial blood pressure and this hypertensive effect in rats with prior exposure to WS 1442 was significantly smaller than in those without. These findings suggest that the hawthorn extract possesses hypotensive action. Pre-exposure to the hawthorn extract also impaired the blood pressure response to phenylephrine. As such, hawthorn may have a modulatory effect on the regulation of blood pressure by a-adrenergic system.
\end{abstract}

Keywords: Arterial blood Pressure; Herbal medicine; Oligomeric procyanidins; Phenylephrine; WS 1442

\section{Introduction}

Hawthorn (Crataegus) belongs to a member of the Rosaceae family, and its major components include flavonoids, amines, triterpene, saponins and oligomeric procyanidin [1,2]. It has been used to treat various cardiovascular conditions including angina, arrhythmias, congestive heart failure and hypertension [1,2]. Crude hawthorn has variable composition of its active components, depending on the environment in which it is grown. As such, the standardization of hawthorn extract is essential to ensure consistent pharmacological actions [3]. Current strategy employs the relative content of flavonoids or oligomeric procyanidins as the standard reference for the hawthorn extract, and one of the standardized extract of hawthorn that are commonly used in clinical trials is WS 1442 [2,4]. WS 1442 is the hydroalcoholic extract of the leaves and flowers of the hawthorn trees and is standardized to contain $18-19 \%$ oligomeric procyanidin. Studies with WS 1442 suggest that hawthorn possesses positive inotropic and anti-arrhythmic effects $[5,6]$. Data obtained from clinical studies also indicates a beneficial cardiovascular effect of WS 1442 in patients with mild to moderate congestive heart failure [4,7-9].

While substantial experimental and clinical studies support the use of hawthorns as an alternative therapy to the management of heart failure, the antihypertensive action of hawthorn has not been well established. In vitro studies indicate that hawthorn caused relaxation in isolated blood vessels [10-13]. Together with the data indicating the effects of hawthorn on the activity of the heart [5,14-16], it is expected that hawthorn may contribute to the regulation of blood pressure. Therefore, the present study examined the effect of the standardized hawthorn extract, WS 1442, on arterial blood pressure in anaesthetized rats. In view of the importance of the sympathetic nervous system on the regulation of blood pressure, the potential of WS 1442 to interfere with the cardiovascular action of the $\alpha$-adrenergic agonist, phenylephrine, was also investigated.

\section{Materials and Methods}

\section{Chemical source and preparation}

Hawthorn (Crataegus) extract WS 1442 (Cardi-Plant ${ }^{\mathrm{TM}}$ Pro, Murdock Madaus Schwabe Professional Products Inc., Springville, Utah, U.S.A.) in capsule form containing $80 \mathrm{mg}$ of dry extract $(5: 1)$ of hawthorn leaves and flowers standardized to $15 \mathrm{mg}$ oligomeric procyanidins (equivalent to a standardization level of $18.75 \%$ ) was used. The capsule was dissolved in 5\% DMSO. Dissolved extracts were passed through a weighed paper filter and then filtered solutions were used for infusion or injection as required. Following the filtration, filters were dried and weighed again such that the real concentration of the dissolved extracts could be determined by subtracting the unfiltered particles.

Phenylephrine and sodium chloride powder were obtained from Sigma (St Louis, MO, U.S.A.) and BDH (Poole, England), respectively. All drugs were dissolved in distilled water and diluted with saline ( $0.9 \%$ sodium chloride solution) into appropriate concentrations for use in experiments. The anesthetics, sodium pentobarbitone powder (Nembutol; Abbott Laboratory, Australia), was dissolved to a final concentration of $70 \mathrm{mg} \cdot \mathrm{ml}^{-1}$ in a mixture of propylene glycol, ethanol and saline at a ratio of 4:1:5 (volume:volume)

*Corresponding author: Susan WS Leung, Department of Pharmacology and Pharmacy, 2/F Laboratory Block, Faculty of Medicine Building, 21 Sassoon Road, Pokfulam, Hong Kong SAR, China, Tel: (852) 2819 9252; Fax: (852) 28170859 ; E-mail: swsleung@hku.hk

Received January 14, 2013; Accepted January 28, 2013; Published January 30, 2013

Citation: Susan WS, Wong MMW, Man RYK (2013) Effects of an Extract of Hawthorn on Arterial Blood Pressure in Anaesthetized Rats. Cardiol Pharmacol 2:104. doi:10.4172/2329-6607.1000104

Copyright: (c) 2013 Susan WS, et al. This is an open-access article distributed under the terms of the Creative Commons Attribution License, which permits unrestricted use, distribution, and reproduction in any medium, provided the original author and source are credited. 


\section{Animal surgery}

Adult male Sprague-Dawley rats $(350 \pm 50 \mathrm{~g})$ were obtained from the Laboratory Animal Unit of the University of Hong Kong. The experimental protocol was approved by the University of Hong Kong Committee on the Use of Live Animals in Teaching and Research. Rats were anesthetized with intraperitoneal injections of sodium pentobarbitone $\left(70 \mathrm{mg} \cdot \mathrm{kg}^{-1}\right)$ for the measurement of blood pressure [17]. The trachea was incubated to facilitate spontaneous breathing. Polyethylene canola (outer diameter $0.96 \mathrm{~mm}$; Portex Ltd. Hythe, Kent, U.K.) filled with saline were inserted into the right jugular vein and left femoral vein for the administration of drugs. Another polyethylene canola was introduced into the right common carotid artery, with the other end connected to a pressure transducer (Gould P23 ID, Statham, U.S.A.) for the measurement of arterial blood pressure. The pressure signals were recorded with a physiograph (Narco Scientific, model MKIV).

\section{Study design}

After surgical procedures, rats were allowed a stabilization period of at least 15 minutes. Saline was continuously infused into rats at a rate of $0.13 \mathrm{ml} . \mathrm{hr}^{-1}$ through left femoral vein to replenish body fluid throughout the experiment. Rats were randomly divided into different groups receiving increasing doses of WS $1442(3.125,6.25,12.5$ and 25 mg.kg $\left.{ }^{-1}\right)$ or the corresponding vehicle, DMSO $(0.625,1.25,2.5$ and $5 \%$ in saline) of the same volume via the jugular vein. They were given a resting period of 15 minutes after administration of each dose, to allow the cardiovascular parameters to return to the baseline values before administration of next dosage. In another series of experiments, rats was infused with WS $1442\left(200 \mathrm{mg} \cdot \mathrm{kg}^{-1} \cdot \mathrm{ml}^{-1}\right)$ at flow rates of 0.052 , $0.072,0.1$ and $0.14 \mathrm{ml} \cdot \mathrm{min}^{-1}$ for 5 minutes, with a 5 minute interval between each infusion. In order to study the influence of WS 1442 on the pressure effect of phenylephrine, WS $1442\left(200 \mathrm{mg} \cdot \mathrm{kg}^{-1} \cdot \mathrm{ml}^{-1}\right)$ was infused into rats at a flow rate of 0.052 or $0.14 \mathrm{ml} . \mathrm{min}^{-1}$ for 7 minutes. After 20 minutes stabilization following infusion, rats were given bolus injections of phenylephrine $\left(1,3\right.$ and $\left.10 \mu \mathrm{g} \cdot \mathrm{kg}^{-1}\right)$ at 15 minute-intervals.

\section{Data and statistical analysis}

All results are expressed as the mean percentage change from baseline value \pm standard error of mean (SEM). The symbol $n$ denotes the number of rats studied. Independent t-test or analysis of variance (ANOVA) with post-hoc Bonferroni test was applied, where appropriate, to determine individual differences between groups of data using a computer statistical package (SPSS, SPSS Inc. Chicago, IL, U.S.A.). A p value $<0.05$ was considered to indicate statistical significance.

\section{Results}

Mean arterial blood pressure before bolus administration of WS 1442 and the vehicle (DMSO) were not significantly different among different groups of rats (104 \pm 3 and $99 \pm 8 \mathrm{mmHg}$ ). Similarly, heart rates were not significantly different among the two groups before drug treatment $\left(292 \pm 7\right.$ and $316 \pm 29$ beats. $\min ^{-1}$ for WS 1442 and vehicle groups). While cumulative administration of vehicle did not significantly affect blood pressure or heart rate, administration of WS 1442 dose-dependently reduced mean arterial blood pressure (Figure 1A) without any significant changes in heart rate (data not shown). The decrease in diastolic blood pressure of WS 1442 was greater than that in systolic blood pressure (Figure 1B). The duration of hypotension induced by WS 1442 were transient, with blood pressure returning to baseline value within 1 minute even at the highest concentrations tested (Figure 1C).

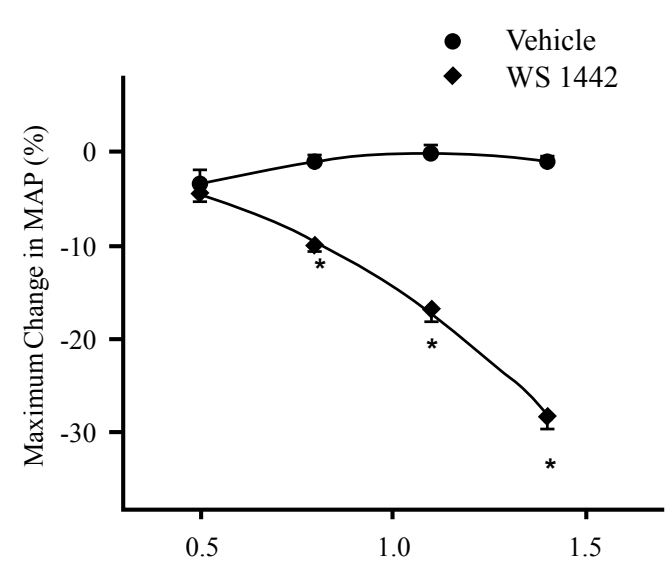

$\log$ Dose (mg. $\left.\mathrm{kg}^{-1}\right)$
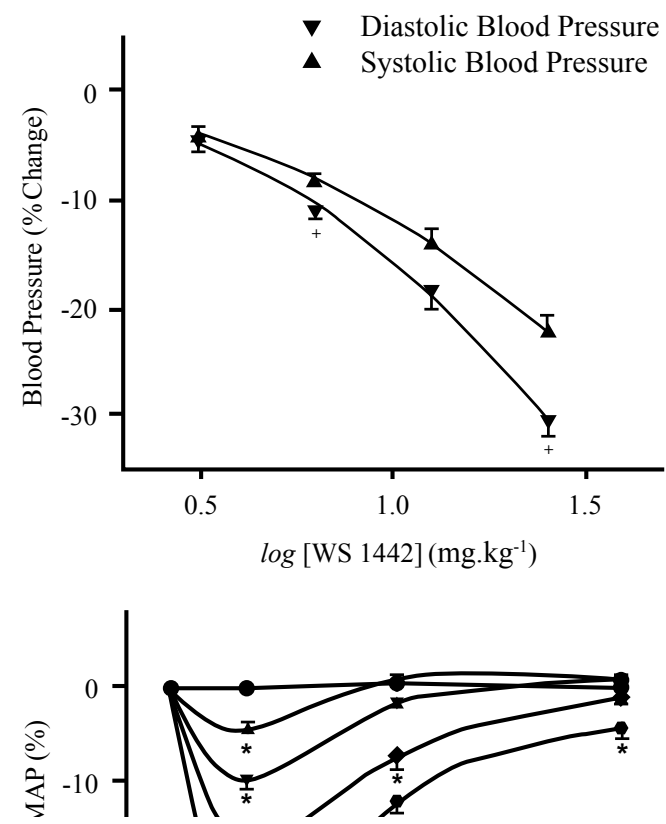

Figure 1: Maximum changes in (A) mean arterial blood pressure (MAP) and (B) diastolic and systolic blood pressure, and (C) the duration of MAP changes following bolus intravenous administration of different doses of WS 1442 or its vehicle, DMSO $(0.5 \%$ in saline $)$, in anaesthetized rats. Data is represented as mean \pm standard error of mean $(n=4-10)$. ${ }^{*} P<0.05$ vs. the vehicle group and $+\mathrm{P}<0.05$ vs. the corresponding values in systolic blood pressure.

Infusion of WS 1442 resulted in sustained decreases in mean arterial blood pressure (Figure 2A) without any significant changes in heart rate (data not shown). Upon the withdrawal of WS 1442 infusion, blood pressure gradually returned to baseline value (Figure 2B). Both the magnitude of the decreases in blood pressure during WS 1442 infusion and the duration of blood pressure lowering effect of WS 1442 following infusion was dose-dependent.

As shown in (Table 1), mean arterial blood pressure and heart rate did not differ among different treatment groups before the bolus injections with phenylephrine at 20 minutes after intravenous infusion with WS $1442\left(10\right.$ and $\left.28 \mathrm{mg} \cdot \mathrm{kg}^{-1} \cdot \mathrm{min}^{-1}\right)$ and the vehicle DMSO $(0.7 \%$ $\left.\mathrm{kg}^{-1} \cdot \mathrm{min}^{-1}\right)$. In the vehicle-treated group, phenylephrine $(1,3$ and 10 $\left.\mu \mathrm{g} . \mathrm{kg}^{-1}\right)$ increased blood pressure in a dose-dependent manner and this increase was smaller in rats that had been exposed previously to WS 1442 infusion (Figure 3). 


\begin{tabular}{|c|c|c|c|}
\hline Treatment Group & $\begin{array}{l}\text { Before Infusion } \\
\text { (0 mins) }\end{array}$ & $\begin{array}{l}\text { During Infusion } \\
\text { (7 mins) }\end{array}$ & $\begin{array}{l}\text { After Infusion } \\
\text { (20 mins) }\end{array}$ \\
\hline \multicolumn{4}{|l|}{$\begin{array}{l}\text { Mean Arterial Blood } \\
\text { Pressure }(\mathrm{mmHg})\end{array}$} \\
\hline $\begin{array}{l}\text { Vehicle (DMSO) } 0.7 \% . \\
\mathrm{kg}^{-1} \cdot \mathrm{min}^{-1}\end{array}$ & $102 \pm 2$ & $111 \pm 2^{+}$ & $110 \pm 2^{+}$ \\
\hline 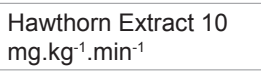 & $106 \pm 1$ & $105 \pm 2^{+}$ & $106 \pm 1$ \\
\hline $\begin{array}{l}\text { Hawthorn Extract } 28 \\
\mathrm{mg} \cdot \mathrm{kg}^{-1} \cdot \mathrm{min}^{-1}\end{array}$ & $119 \pm 2^{*}$ & $92 \pm 3^{*+}$ & $113 \pm 3^{+}$ \\
\hline \multicolumn{4}{|l|}{ Heart Rate (bests/min) } \\
\hline $\begin{array}{l}\text { Vehicle (DMSO) 0.7\%. } \\
\mathrm{kg}^{-1} \cdot \mathrm{min}^{-1}\end{array}$ & $323 \pm 4$ & $325 \pm 5$ & $332 \pm 4$ \\
\hline $\begin{array}{l}\text { Hawthorn Extract } 10 \\
\mathrm{mg} \mathrm{kg}^{-1} \cdot \mathrm{min}^{-1}\end{array}$ & $323 \pm 3$ & $323 \pm 3$ & $330 \pm 3$ \\
\hline 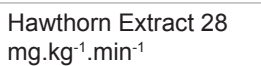 & $324 \pm 2$ & $326 \pm 2$ & $332 \pm 4$ \\
\hline
\end{tabular}

Data is represented by mean \pm SEM with $n=5$ for all groups. ${ }^{*}<0.05$ vs. the vehicle group and $+P<0.05$ vs. the corresponding values before infusion.

Table 1: Effect of intravenous infusion of WS 1442 (200 mg.kg-1.ml-1) at flow rates of 0.05 or $0.14 \mathrm{ml} . \mathrm{min}-1$, and of its vehicle, dimethyl sulfoxide (DMSO, $5 \% . \mathrm{kg}-1$. $\mathrm{ml}-1$ ), at a flow rate of $0.14 \mathrm{ml}$.min- 1 , for 7 mins on mean arterial blood pressure and heart rate in anaesthetized rats.

\section{Discussion}

Hawthorn has been used as an alternative therapy for various cardiovascular disorders [2,18-20]. Clinical efficacies of different hawthorn extract for treatments of heart failure have been examined $[7,8,21]$. Our present in vivo studies indicate that in addition to improving heart functions $[5,14,16]$, hawthorn extract exerts beneficial effect in the cardiovascular system by directly lowering arterial blood pressure as well as by modifying the pressure responses to sympathetic stimulation by phenylephrine.

In the present study, the blood pressure and heart rates were measured in rats anaesthetized with pentobarbitone. The pentobarbitone-induced anesthesia results in inhibition of the baroreceptor reflex. This accounts for the absence of changes in the heart rate when the blood pressure was reduced by WS 1442 or increased by phenylephrine. While this is a limitation for hemodynamic study, the inhibition of the baroreceptor reflex would permit the examination of the effect of WS 1442 on the heart rate per sec. Moreover, the actual effect of WS 1442 on the blood pressure would be unmasked, as the increase or decrease of blood pressure would not be compensated by the changes in heart rate.

Like most herbal medicine, hawthorn is not a single entity but consists of different components. In view of the large content of flavonoids and oligomeric procyanidins, it is logical to assume that these components are responsible for the biological activities of hawthorn. In agreement with this assumption, flavonoids that are isolated from the hawthorn plants mimicked the ability of hawthorn extracts in inducing inotropic effects on the heart and vasodilatation in blood vessels $[5,12]$. Clearly, the relative content of flavonoids in different hawthorn plants or extracts is likely to differ significantly, due to variations in the source of the crude hawthorn as well as in the manufacture procedures of the different hawthorn preparations. As such, it is highly likely that the biological effects of different hawthorn preparations vary largely $[3,12,22]$. Commercially available hawthorn extracts currently used the content of flavonoids or oligomeric procyanidins for standardization to ensure consistent pharmacological actions $[2,4]$. Our present in vivo experiments suggest that the standardized form, WS 1442, which contains about $18.75 \%$ oligomeric procyanidins, has significant blood pressure lowering effect. The findings that WS 1442 caused greater decrease in diastolic blood pressure than in systolic blood pressure

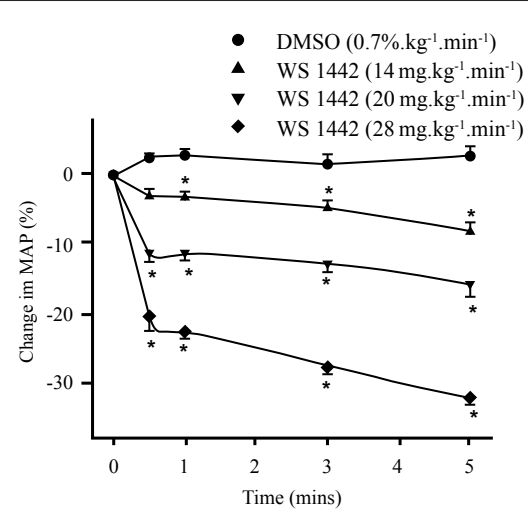

B

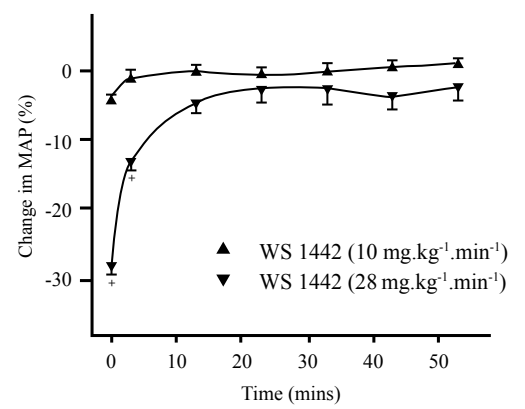

Figure 2: Changes in mean arterial blood pressure (MAP) (A) during and (B) after intravenous infusion of different doses of WS 1442 or its vehicle in anaesthetized rats. Data is represented as mean \pm standard error of mean $(n=3-5)$. ${ }^{*} P<0.05$ vs. the vehicle group and $+P<0.05$ vs. the corresponding values in rats that were treated with WS $1442\left(10 \mathrm{mg} \cdot \mathrm{kg}^{-1} \cdot \mathrm{min}^{-1}\right)$.

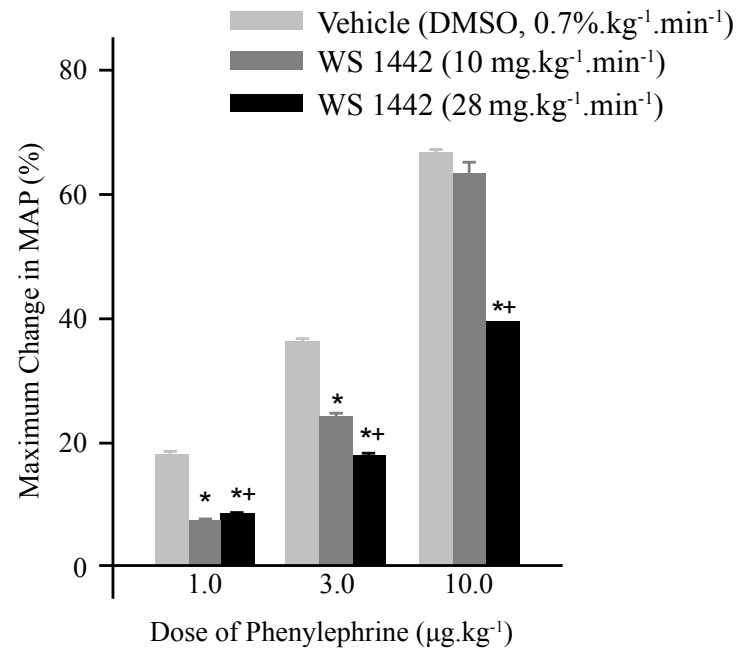

Figure 3: Changes in mean arterial blood pressure (MAP) induced by different doses of phenylephrine 20 minutes after the infusion of WS 1442 or its vehicle for 7 minutes in anaesthetized rats. Data is represented as mean \pm standard error of mean $(n=5)$. ${ }^{*} P<0.05$ vs. the vehicle group and $+P<0.05$ vs. the corresponding values in rats that were treated with WS $1442\left(10 \mathrm{mg} \cdot \mathrm{kg}^{-1} \cdot \mathrm{min}^{-1}\right)$.

suggest that its blood pressure lowering effect is attributed to a greater extent by its effect on vascular tone than on heart function. This is supported by experimental studies demonstrating that hawthorn extract is capable of relaxing isolated aorta and mesenteric arteries from 
rats [10-12], and by the present study in anaesthetized rats that WS 1442 reduced blood pressure without affecting heart rate. Therefore, WS 1442 most likely reduces peripheral vascular resistance (by causing vasodilatation) to lower blood pressure.

Clinically, the doses of hawthorn extracts given to patients ranged from 80 to $900 \mathrm{mg}$ taken twice daily orally. At present, pharmacokinetic data on the plasma concentration of the hawthorn extracts or its flavonoid content following the oral intake is limited $[23,24]$. Therefore, it is not possible to compare the concentrations of WS 1442 used in the present study and those used clinically. In a previous study in human, intake of $42.1 \mathrm{mg}$ procyanidins (in the form of a cocoa drink) results in a peak plasma concentration of procyanidins of at least $4.11 \pm 0.81$ $\mu \mathrm{M}$, which is equivalent to $1.19 \mathrm{mg} / \mathrm{L}$ [25]. Since an average human has about $5 \mathrm{~L}$ of blood, the amount of procyanidins that can be absorbed into the blood circulation is about $5.95 \mathrm{mg}$. Therefore, approximately $14 \%$ of the total procyanidins consumed orally can be absorbed into the circulation. WS 1442 is standardized to contain $18.75 \%$ oligomeric procyanidins. As such, the level of oligomeric procyanidins intake from the daily dose of $160-1800 \mathrm{mg}$ WS 1442 is estimated to be $30-338 \mathrm{mg}$, and so the plasma concentration of procyanidins after WS 1442 supplement is within the range of $4.2-47.3 \mathrm{mg}$, which is equivalent to $0.06-0.68 \mathrm{mg}$ $\mathrm{kg}^{-1}$ (assuming that an average adult weighs $70 \mathrm{~kg}$ ). In the present study, doses of WS 1442 and hence procyanidins injected intravenously into rats ranged from $3.125-25 \mathrm{mg} . \mathrm{kg}^{-1}$ and $0.59-4.69 \mathrm{mg} \cdot \mathrm{kg}^{-1}$, respectively. Taken into consideration that rats have higher metabolic rate compared to humans, and that hawthorn is well tolerated even at relatively high doses $[7,8,26]$, the concentrations used in the present study may still be relevant for those used in human consumption.

Clinical studies indicate that a daily intake of $500 \mathrm{mg}$ hawthorn extract with $\geq 1.8 \%$ vitexin-2-rhamnosides for 10 weeks did not reduce blood pressure in hypertensive patients [27], whereas a daily intake of $1200 \mathrm{mg}$ hawthorn extract containing 2.2\% flavonoids for 16 weeks modestly reduced diastolic blood pressure in diabetic patients [28]. These studies suggest that hawthorn extract produces antihypertensive effect only at relatively high daily dosage. Alternatively, higher level of oligomeric procyanidins may be associated with antihypertensive action of hawthorn extract. Indeed, Brixius et al. demonstrated that the fraction containing oligomeric procyanidins is responsible for the relaxation of rat aorta induced by WS 1442 [12]. On the other hand, oral administration of the flavonoid hyperoside extract of hawthorn for 4 weeks was more effective than that of the crude form of hawthorn in preventing the development of high blood pressure caused by inhibition of nitric oxide synthase [29]. Both the oligomeric procyanidins and the flavonoid hyperoside extract of hawthorn are capable of increasing the activity of nitric oxide synthase and hence the release of nitric oxide, which may explain the antihypertensive effect of WS 1442 observed in the present study. While the short half-life of nitric oxide also seems to be in line with the transient hypotensive effect of WS 1442, further experiments need to be performed to confirm the role of nitric oxide in the effect of WS 1442 on blood pressure in vivo.

In addition to an acute direct effect of WS 1442 on blood pressure, WS 1442 appears to modulate the response of the cardiovascular system to $\alpha$-adrenergic stimulation by phenylephrine. The sympathetic nervous system is one of the major systems involved in the regulation of arterial blood pressure. Stimulation of the sympathetic nervous system results in increases in arterial blood pressure due to increases in peripheral resistance and cardiac output through activation of $\alpha$-adrenergic and $\beta$-adrenergic receptors, respectively. As such, the ability of WS 1442 to reduce the blood pressure elevating effect of phenylephrine suggests a therapeutic potential of WS 1442 as an antihypertensive agent, particularly as an adjunct therapy like the antihypertensive $\alpha$-adrenergic receptor blockers.

One limitation in the use of WS 1442 as a direct hypotensive agent is its rather short duration. Administration of WS 1442 intravenously in rats resulted in rapid and potent reduction in blood pressure, but the blood pressure returned to baseline value within one minute. This transient hypotensive action of WS 1442 may be due to a rapid desensitization of the response to WS 1442. That WS 1442 was able to lower blood pressure in a cumulatively dose-dependent manner suggests that desensitization is unlikely to explain for the short duration of action. Alternatively, WS 1442 may be rapidly eliminated from the bloodstream. While the direct blood pressure lowering action of WS 1442 is transient, the modulatory action of WS 1442 against the effect of phenylephrine is rather long-lasting; as such effect persists for more than 30 minutes after the infusion of WS 1442 even for the low concentration tested in this study $\left(10 \mathrm{mg} \cdot \mathrm{kg}^{-1} \cdot \mathrm{min}^{-1}\right)$. This concentration approaches the dosage used as a health supplement, which is recommended to be $900 \mathrm{mg}$ capsule of WS 1442 taken twice daily.

In conclusion, the present work has demonstrated that the commercially available preparation of the hawthorn extract, WS 1442, effectively reduces blood pressure and this antihypertensive action is likely attributed to its effect on vascular tone. Furthermore, WS 1442, at the concentration used as a health supplement, appears to modulate the vascular response to $\alpha$-adrenergic stimulation in the regulation of blood pressure.

\section{Acknowledgements}

We would like to acknowledge the scientific advice of Prof. David D Ku (University of Alabama, U.S.A.), and the technical support kindly provided by $\mathrm{Mr}$ Godfrey SK Man. We are also grateful to the Laboratory Animal Unit for the supply and husbandry of rats for this study.

\section{References}

1. Chang Q, Zuo Z, Harrison F, Chow MS (2002) Hawthorn. J Clin Pharmacol 42 605-612.

2. Rigelsky JM, Sweet BV (2002) Hawthorn: Pharmacology and Therapeutic Uses. Am J Health System Pharm 59: 417-422.

3. Vierling W, Brand N, Gaedcke F, Sensch KH, Schneider E, et al. (2003) Investigation of the pharmaceutical and pharmacological equivalence of different Hawthorn extracts. Phytomedicine 10: 8-16.

4. Pittler $\mathrm{MH}$, Schmidt K, Ernst E (2003) Hawthorn extract for treating chronic heart failure: meta-analysis of randomized trials. Am J Med 114: 665-674.

5. Schwinger RH, Pietsch M, Frank K, Brixius K (2000) Crataegus specia extract WS 1442 increases force of contraction in human myocardium cAMP. independently. J Cardiovasc Pharmacol 35: 700-707.

6. Veveris M, Koch E, Chatterjee SS (2004) Crataegus special extract WS 1442 improves cardiac function and reduces infarct size in a rat model of prolonged coronary ischemia and reperfusion. Life Sci 74: 1945-1955.

7. Zapfe jun G (2001) Clinical efficacy of crataegus extract WS 1442 in congestive heart failure NYHA class II. Phytomedicine 8: 262-266.

8. Tauchert M (2002) Efficacy and safety of crataegus extract WS 1442 in comparison with placebo in patients with chronic stable New York Heart Association class-III heart failure. Am Heart J 143: 910-915.

9. Habs M (2004) Prospective, comparative cohort studies and their contribution to the benefit assessments of therapeutic options: heart failure treatment with and without Hawthorn special extract WS 1442. Forsch Komplementarmed Klass Naturheilkd 11: 36-39.

10. Chen ZY, Zhang ZS, Kwan KY, Zhu M, Ho WK, et al. (1998) Endotheliumdependent relaxation induced by hawthorn extract in rat mesenteric artery. Life Sci 63: 1983-1991.

11. Kim SH, Kang KW, Kim KW, Kim ND (2000) Procyanidins in crataegus extract evoke endothelium-dependent vasorelaxation in rat aorta. Life Sci 67: 121-131. 
Citation: Leung SWS, Wong MMW, Man RYK (2013) Effects of an Extract of Hawthorn on Arterial Blood Pressure in Anaesthetized Rats. Cardiol Pharmacol 2:104. doi:10.4172/2329-6607.1000104

12. Brixius K, Willms S, Napp A, Tossios P, Ladage D, et al. (2006) Crataegus special extract WS 1442 induces an endothelium-dependent, NO-mediated vasorelaxation via eNOS-phosphorylation at serine 1177. Cardiovasc Drugs Ther 20: 177-184.

13. Anselm E, Socorro VF, Dal-Ros S, Schott C, Bronner C, et al. (2009) Crataegus special extract WS 1442 causes endothelium-dependent relaxation via a redoxsensitive src- and akt-dependent activation of endothelial NO synthase but not via activation of estrogen receptors. J Cardiovasc Pharmacol 53: 253-260.

14. Müller A, Linke W, Klaus W (1999) Crataegus extract blocks potassium currents in guinea pig ventricular cardiac myocytes. Planta Med 65: 335-339.

15. Garjani A, Nazemiyeh H, Maleki N, Valizadeh H (2000) Effects of extracts from flowering tops of Crataegus meyeri A. Pojark. on ischaemic arrhythmias in anaesthetized rats. Phytother Res 14: 428-431.

16. Long SR, Carey RA, Crofoot KM, Proteau PJ, Filtz TM (2006) Effect of hawthorn (Crataegus oxycantha) crude extract and chromatographic fractions on multiple activities in a cultured cardiomyocyte assay. Phytomedicine 13: 643-650.

17. Leung SW, Zhu DY, Man RY (2010) Effects of the aqueous extract of Salvia Miltiorrhiza (danshen) and its magnesium tanshinoate B-enriched form on blood pressure. Phytother Res 24: 769-774.

18. De Smet PA (2002) Herbal remedies. N Engl J Med 347: 2046-2056.

19. Fong HH, Bauman JL (2002) Hawthorn. J Cardiovasc Nurs 16: 1-8.

20. Chang WT, Dao J, Shao ZH (2005) Hawthorn: potential roles in cardiovascular disease. Am J Chin Med 33: 1-10.

21. Degenring FH, Suter A, Weber M, Saller R (2003) A randomised double blind placebo controlled clinical trial of a standardised extract of fresh Crateagus berries (Crataegisan) in the treatment of patients with congestive heart failure NYHA II. Phytomedicine 10: 363-369.

22. Rodriguez ME, Poindexter BJ, Bick RJ, Dasgupta A (2008) A comparison of the effects of commercially available hawthorn preparations on calcium transients of isolated cardiomyocytes. J Med Food 11: 680-686.

23. Holt RR, Lazarus SA, Sullards MC, Zhu QY, Schramm DD, et al. (2002) Procyanidin dimer B2 [epicatechin-(4beta-8)-epicatechin] in human plasma after the consumption of a flavanol-rich cocoa. Am J Clin Nutr 76: 798-804.

24. Zuo Z, Zhang L, Zhou L, Chang Q, Chow M (2006) Intestinal absorption of hawthorn flavonoids -in vitro, in situ and in vivo correlations. Life Sci 79: 24552462

25. Steinberg FM, Holt RR, Schmitz HH, Keen CL (2002) Cocoa procyanidin chain length does not determine ability to protect LDL from oxidation when monomer units are controlled. J Nutr Biochem 13: 645-652.

26. Daniele C, Mazzanti G, Pittler MH, Ernst E (2006) Adverse-event profile of Crataegus spp.: a systemic review. Drug Saf 29: 523-535.

27. Walker AF, Marakis G, Morris AP, Robinson PA (2002) Promising hypotensive effect of hawthorn extract: a randomized double-blind pilot study of mild, essential hypertension. Phytother Res 16: 48-54.

28. Walker AF, Marakis G, Simpson E, Hope JL, Robinson PA, et al. (2006 Hypotensive effects of hawthorn for patients with diabetes taking prescription drugs: a randomized controlled trial. $\mathrm{Br} \mathrm{J}$ Gen Pract 56: 437-443.

29. Kocyildiz ZC, Birman H, Olgac V, Akgun-Dar K, Melikoglu G, et al. (2006) Crataegus tanacetifolia leaf extract prevents L-NAME-induced hypertension in rats: a morphological study. Phytother Res 20: 66-70. 